\title{
8 \\ The Alignment of the Economic Institutions on Fossil Fuel Subsidies
}

\author{
Synergies, but Definitions Can Be Divisive
}

The three preceding chapters have explored the economisation of fossil fuel subsidies by the G20, the OECD and the IMF, all three of which addressed fossil fuel subsidies as an economic issue. Even when the environmental consequences of fossil fuel subsidies were highlighted, it was done in a manner framing these consequences in economic terms, for example, as wasteful consumption or as non-priced externalities. While the three institutions agreed on the importance of a reform of fossil fuel subsidies due to their environmental and economic consequences, they also differed in how they addressed these subsidies. Most notably, the IMF adopted a radical definition of fossil fuel subsidies based on the Pigouvian notion of corrective taxes, which stood out against the more established definition of the OECD. Thus, the economisation was more ideal-typical in the case of the IMF. The G20 skirted the issue of fossil fuel subsidy definition but worked closely with the OECD. The chapter proceeds with a comparison of the three institutions and demonstrates that economisation may lead to diverging framings of the issue in economic terms. Altogether, they constitute core institutions within the fossil fuel subsidy complex, a complex characterised by synergistic relations (Verkuijl and van Asselt, 2020). Subsequently, the chapter outlines how this divergence was driven by the differences in worldview, policy entrepreneurship and the degree of autonomy of the International Organisation (IO) bureaucracy from principals. Yet, the similarities between their worldviews (they agreed on a range of fundamental issues), institutional interaction and overlapping memberships pulled in the direction of convergence between the institutions. Finally, there is a discussion on the consequences of this divergence at the international and domestic levels (conflicting estimates of fossil fuel subsidies and discussions of which definition to use), while the convergence between the institutions was important for the attention to the issue and the norm of fossil fuel subsidy reform. 


\subsection{How They Align}

\subsubsection{Types of Output}

The institutions differed considerably in the form of their output. The G20's output was mainly regulatory with a crucial normative component, most notably in 2009 when it propelled both the concept of fossil fuel subsidies and the norm of fossil fuel subsidy reform high up international and domestic agendas. Subsequent G20 output focused on gathering knowledge about fossil fuel subsidies (especially by requesting such knowledge from four IOs) and directly holding G20 member states accountable to the norm through self-reporting and voluntary peer reviews. The output of the OECD consisted of knowledge but focused more on the cognitive aspects of fossil fuel subsidies by producing extensive knowledge about fossil fuel subsidies, including within individual countries. This knowledge production had a normative aspect in that its purpose was to identify subsidies that should be reformed or phased out. The OECD also disseminated knowledge about fossil fuel subsidies and how to reform them through formal and informal channels such as workshops and direct involvement with countries, including G20 peer reviews, which they chaired. The IMF's output can be divided into two strands. The first strand provides incentives for fossil fuel subsidy reform through the conditionalities of the programmes. The second strand is knowledge based and centres on the IMF's definition of fossil fuel subsidies as including non-priced externalities. This definition has a normative component in 'getting the price right' through pricing externalities and expanding the applicability of the norm of fossil fuel subsidy reform, as well as a cognitive component in framing fossil fuel subsidies in terms of macroeconomic consequences and producing knowledge about the level of fossil fuel subsidies in countries around the world.

The relationship between the G20 and the OECD can be described as synergistic, with the two institutions focusing on different tasks, and the OECD supporting the G20's efforts to promote the norm of fossil fuel subsidy reform through cognitive output. This division of labour is due to the $\mathrm{G} 20$ requesting that the OECD provides such support, and, in more general terms, the OECD fulfilling secretariat functions for the G20 in several areas. The relationship between on the one hand the two institutions and on the other the IMF has rather been one of co-existence, with a sometimes conflictive relationship between the IMF and the OECD as regards the issue of subsidy definitions (for the argument that non-priced externalities should not be treated as a subsidy, see Steenblik, 2014).

\subsubsection{Scope and Actors Addressed}

For all three institutions, it is possible to distinguish between output that is global in reach and output that is more targeted. The G20 commitment and the resulting 
self-reports and peer reviews focused on the G20 members, yet much of the cognitive output produced by the IEA, OECD, OPEC and the World Bank at the request of the G20 was global in reach. Likewise, most of the OECD's output concerned its members plus seven of the largest emerging economies, yet other output, for instance its publications on how to define fossil fuel subsidies, had a global reach. The IMF's first, incentive-based strand targeted countries with financial problems, whereas its second, ideational output on the non-pricing of externalities targeted virtually all countries. Hence, there is a significant overlap in the countries that they address. In the case of synergistic relationships, such as the one between the OECD and the G20, this should not imply any risk of conflicting output. Conflicting output are more likely when institutions address a set of countries with regard to a particular issue but use differing approaches, such as the divergence between the OECD and the IMF regarding the definition of fossil fuel subsidies. Yet, this did not result in conflict at the domestic or international levels, as discussed in detail in Section 8.3. In terms of the government institutions they interacted with, there is also a considerable overlap, as the circle of fossil fuel subsidy experts in each country is limited and these experts are often based in finance ministries, which interact with all three institutions.

\subsubsection{Cognitive Dimensions}

All three institutions frame fossil fuel subsidies in economic and environmental terms. The environmental framing is perhaps most interesting, as fossil fuel subsidies were previously grouped together with other subsidies and not singled out because of their environmental impact. Distinguishing fossil fuel subsidies from other subsidies implies an emphasis on their environmental consequences.

The G20 left open both the definitional question and the closely related questions of which fossil fuel subsidies exist in individual countries and their size. Importantly, the G20 has primarily framed fossil fuel subsidies in terms of climate change as well as macroeconomic consequences, while the importance of reducing poverty was also stressed. The fiscal impact was not mentioned. The OECD has mainly framed the subsidies in environmental and fiscal terms. While the macroeconomic consequences of fossil fuel subsidies have also received some attention (but not been included in the estimates of their consequences), the distributional impact has hardly been addressed at all. The IMF has adopted a Pigouvian framing, which includes the non-pricing of externalities as a subsidy and highlights the environmental consequences while framing them in terms of their macroeconomic impact. The fiscal and distributional consequences have mainly been emphasised by the Fund outside its knowledge output regarding getting prices right through the pricing of externalities, the fiscal consequences being important to the IMF's first 
strand. These differences in framing are not conflictive in themselves, since the institutions merely highlight different aspects of fossil fuel subsidies while agreeing on the importance of their environmental and economic consequences. Yet, the difference between the IMF' economisation of fossil fuel subsidies based on textbook economics and the OECD's economisation based on fiscal concerns underscores how economisation was more ideal-typical in the case of the IMF (see also Chapter 1).

In political terms, the differences in definitions between the OECD and the IMF are more important, since they lead to different estimates of the size of fossil fuel subsidies. The IMF estimated that fossil fuel subsidies were ten, in the case of some countries such as the United States even a hundred, times higher than the OECD did (IMF, 2018a; OECD, 2020a). In this way, rather conflicting bodies of knowledge were produced by the two institutions. While the two subsidy definitions de facto measure different phenomena, they are both generally referred to as measuring fossil fuel subsidies. Yet, it is important to bear in mind that both the IMF and the OECD mainly measured the size of subsidies in monetary (although the former focused on macroeconomic costs and the latter on fiscal ones) and quantitative terms, rather than, for example, the number of policies or the climate impact measured in tons of $\mathrm{CO}_{2} \mathrm{e}$. This monetary and quantitative approach to measuring and addressing a problem constitutes one fundamental cognitive aspect of economisation. Hence, I argue that the cognitive differences between the institutions is best understood as different kinds of economisation, rather than as economic and non-economic ways of addressing fossil fuel subsidies.

\subsubsection{Normative Dimensions}

All three institutions have promoted the norm of fossil fuel subsidy reform. It is notable that three economic institutions all defined the climate consequences of fossil fuel subsidies as an important reason for reforming them. They also shared a concern over inefficiency and opposition to subsidies as distortionary and leading to economically suboptimal outcomes (e.g. 'wasteful consumption' as the G20 2009 put it). Defining economic efficiency as a key objective is a crucial dimension of the economisation of fossil fuel subsidies of the three institutions, although most pronounced within the IMF. Divergence appeared rather in terms of the IMF's linking of the norm with carbon pricing, a link that was rooted in Pigouvian economics.

This divergence had implications for the application of the norm of fossil fuel subsidy reform, which the IMF found was salient to several situations (whenever 
a fuel was sold at a price that did not include its social costs) in which the OECD did not find that it applied. There are also situations in which the OECD identified fossil fuel subsidies that the IMF did not, for example, consumption subsidies that do affect prices. This divergence is important, because the two institutions identify different issues as problematic in terms of fossil fuel subsidies. For the IMF, it is the non-pricing of externalities, for the OECD policies subsidising the consumption and production of fossil fuels. Both agree that consumption subsidies lowering the price of fossils below the benchmark price including value-added tax (VAT) constitutes a subsidy, as do production subsidies. The IMF also included production subsidies in its estimate and used OECD estimates of these subsidies, which nonetheless amounted to a minuscule part of the total global fossil fuel subsidies in the IMF estimate (about USD 17 billion out of 5,300 billion). Likewise, the OECD is generally also in favour of environmental taxes, including carbon taxes (Bernstein, 2001; Ruffing, 2010).

Consequently, the two institutions recommend different actions to implement the norm of fossil fuel subsidy reform. While the IMF recommends adopting taxes corresponding to the externalities from fuel use, the OECD recommends phasing out specific policies. The IMF's approach is clearly rooted in the notion of Pigouvian taxation, whereas the OECD's approach is less specific in terms of ideational underpinnings but fits with the paradigm of liberal environmentalism. Liberal environmentalism differs from neoclassical environmental economics in that it is a more encompassing norm complex rather than an academic paradigm with a more specific problem definition (pollution as an externality) and policy solutions (pricing). Nonetheless, there are considerable overlaps, and it is worth noting that one of the fathers of liberal environmentalism and of the OECD's approach to sustainable development, David Pearce, gave a presentation at one of the earliest OECD workshops on environmentally harmful subsidies. Although Pearce advocated Pigouvian taxation to address externalities (Pearce, 2002b), he did not treat the absence of such taxation as a subsidy (a notion that was developed only later; see Clements et al., 2013; Hodas, 2006), but as a way of addressing environmental degradation, a problem defined as distinct from the existence of subsidies (Pearce, 2002a).

\subsubsection{Incentives}

In terms of incentives, the relationship between the three institutions is more synergistic. The IMF is the institution that has provided the strongest incentives for fossil fuel subsidy reform, but these incentives suit the output of the other two 
institutions. Most importantly, the IMF making fossil fuel subsidy reform a condition for loans under the adjustment programmes has led to fossil fuel subsidy reforms in the G20 members Indonesia and (after the Pittsburgh commitment) Argentina ${ }^{1}$ as well as non-G20 countries including Egypt and Ukraine. Thus, IMF incentives have supported the norm of fossil fuel subsidy reform both within and beyond the G20 by inducing countries to reform these subsidies.

\subsection{Causes of Alignment}

Factors pulling in the direction of convergence and divergence shape the overall pattern of alignment in terms of synergy on fundamental issues and some degree of diverging (although rarely conflicting) ideas concerning definitions, especially between the IMF and the OECD. Regarding convergence, the fundamental elements of the institutional worldviews shaped the basic shared approach to fossil fuel subsidies as an issue that was problematic for environmental and economic reasons. The environmental reasons were mainly conceived of in economic terms as problematic due to their economic costs. Institutional interaction is another important factor for convergence, particularly between the G20 and the OECD, which interacted with other as well as several of the same institutions, particularly the IEA and the World Bank. On a fundamental level, interaction also mattered in terms of the Pittsburgh commitment lifting the topic to a new level internationally, including within the OECD and more indirectly the IMF (see Chapters 6 and 7). Overlap in terms of membership also pulled in the direction of convergence, since several states are members of all three institutions, most notably the largest developed economies. Yet, also institutions that do not overlap to the same extent, most notably the Friends of Fossil Fuel Subsidy Reform, have produced similar output, indicating that convergence can also happen without overlapping membership.

On the other hand, the divergence between the institutions, particularly the IMF and the OECD, has been driven by factors, which influenced the institutions in different ways. The institutional interaction that influenced the OECD did not influence the IMF to the same extent, since there was no request to address fossil fuel subsidies and thus the IMF did not interact in the same way with the G20, the IEA, the World Bank and OPEC. Rather the IMF addressed the issue on the initiative of IMF staff, which more than OECD staff induced their organisation to address fossil fuel subsidies. IMF staff acting as policy entrepreneurs are also the main reason why the IMF to a larger degree than the OECD framed fossil fuel

\footnotetext{
${ }^{1}$ Although fossil fuel subsidy reform in Argentina was effectively reversed within a short period of time (IMF, 2019i).
} 
subsidies in terms derived from environmental economics: IMF staff linked the macroeconomic and environmental framing of such subsidies on the basis of the notion of getting the price right.

The differences in how the organisations addressed fossil fuel subsidies was also influenced by more specific differences between their worldviews: the IMF defined the environmental impact in the aforementioned neoclassical way, and the OECD defined fossil fuel subsidies in a fashion reflecting how it had addressed other subsidies. The G20 was much less specific in how it defined fossil fuel subsidies and the applied the norm of fossil fuel subsidy reform, but to a large extent relied on its member states and other institutions, notably the OECD.

The degree of autonomy of the IO bureaucracies proved to be an important scope condition for the influence of the worldview and policy entrepreneurs, and thus also shaping the divergence between the institutions. This is evident in that the IMF, to a greater degree than the OECD, adopted positions running against the preferences of its member states, most notably the claim that developed countries have significant fossil fuel subsidies. The OECD had less autonomy and only received the mandate to scrutinise its members' subsidies after the G20 commitment. The differences between the two organisations demonstrate that differences in membership and voting rules did not have an impact, as the IMF contradicted member states that are more influential within the IMF than within the OECD, especially the United States. Arguably, if the IMF had the same degree of autonomy as the OECD Secretariat, its position would have been more similar to that of the OECD.

\subsection{The Consequences of Alignment}

The alignment of the three institutions had important consequences both at the international and the domestic levels.

\subsubsection{The International Level}

The international level is the level where the combined output of the three institutions had the greatest impact. Especially the G20 managed to ensure the inclusion of the issue of fossil fuel subsidies and the norm of fossil fuel subsidy reform on the agenda of other international institutions, which led to new commitments to fossil fuel subsidy reform within Asia-Pacific Economic Cooperation (APEC), the North American Leaders' Forum and indirectly the Sustainable Development Goals (SDGs), and even to the creation of an institution dedicated to fossil fuel subsidy reform, Friends. In addition, the G20 commitment led to other international institutions producing new knowledge about these subsidies, including the OECD. 
Together with the IMF's cognitive output on fossil fuel subsidies, they significantly increased the knowledge of such subsidies based on the framing of them as economically and environmentally costly. While it is not possible to provide a full counterfactual analysis, I would argue that without the G20 commitment, the international efforts to address fossil fuel subsidies would have looked different, with fewer or no commitments to reform. Likewise, without the OECD output, there would have been less knowledge about fossil fuel subsidies especially in developed countries. Moreover, without the IMF's output, carbon pricing and the non-pricing of externalities would not have been linked to fossil fuel subsidies.

The synergy between the G20 and the OECD reinforced their respective outputs. The OECD in particular benefitted from the G20 commitment, which lifted its own involvement to a new level (see Chapter 6) and opened the doors for OECD subsidy experts to be part of G20 peer reviews, SDG working groups on the reporting of efforts to fossil fuel subsidies, and so forth. The differences between the OECD and IMF definitions of fossil fuel subsidies also played out at the international level, particularly in the context of the G20 peer reviews and the SDG fossil fuel subsidy working group. In both cases, there was a discussion of which definition to use, and in both cases, approaches closely aligned with the OECD definition won the day. The IMF's approach was discussed and to some degree also applied in the SDG report on how measure fossil fuel subsidies (UNEP et al., 2019) and the first G20 peer reviews (of China and the United States), but not in subsequent peer reviews. Thus, the potential for conflict between the two different definitions did not undermine the efforts to address fossil fuel subsidies, but merely led to expert discussions of their relative merits and in the case of the Chinese and US peer reviews, to discussions of the pricing of externalities in the two countries.

\subsubsection{The Domestic Level}

The three institutions had less of a discernible effect at the domestic level than at the international level (see Chapters 5, 6 and 7). In the five countries studied, those that reformed their fossil fuel subsidies did so mainly because of domestic pressure. Nonetheless, the fact that the institutions all promoted the norm of fossil fuel subsidy reform meant that the prevailing combined effect was one of synergy with the institutions reinforcing each other. The OECD and the IMF were important in picking up the baton from the G20 and ensuring that the issue remained on the (political to a larger degree than the public) agenda after the initial attention caused by the G20 commitment had died down. The IMF and the OECD also had the ability to produce new knowledge about the issue in a way that the G20 did not. The synergistic relationship between the G20 and the OECD played an important role 
primarily regarding G20 countries - especially those undergoing peer reviews - in terms of the OECD using its expertise on fossil fuel subsidies in general and about the countries subject to peer review in particular.

Regarding the definitional divergence between the IMF and the OECD, actors in developed countries studied picked up the IMF estimates of fossil fuel subsidies within their country in particular. Most notably, the UK House of Commons Environmental Audit Committee discussed the different approaches and the different estimates of UK subsidies provided by the two institutions (House of Commons, 2013). This Committee based its conclusions on the OECD definition. In the context of this debate and in the media in all the three developed countries, the IMF's estimate sometimes received attention because of the higher figures. Yet, all things considered, the OECD definition has been more important (also in the context of the G20 peer reviews), and the relationship between the two definitions has been one of co-existence rather than conflict.

\subsection{Summary}

The three institutions have worked to promote the norm of fossil fuel subsidy reform. More specifically, they framed fossil fuel subsidies as undesirable because of their environmental and economic consequences, though the environmental consequences were framed in economic terms. Although the OECD and the IMF diverged regarding the definition of fossil fuel subsidies, the relationship was generally one of co-existence rather than conflict. Particularly the G20 and the OECD had a synergetic relationship, in which the G20 requested the OECD to provide an analysis of fossil fuel subsidies, which lifted the OECD involvement with the topic to a new level. The OECD also influenced the content of the G20 output. The divergence between the OECD and the IMF centred on the IMF's inclusion of the non-pricing of externalities in its definition of fossil fuel subsidies, a framing rooted in the neoclassical notion of getting prices right. and constituting an even more ideal-typical case of economisation than the OECD's framing. This divergence had ramifications for both the international and domestic levels in terms of conflicting estimates of fossil fuel subsidies and discussions of which definition to use, for example, in the context of the SDGs. Yet, the synergy between the institutions regarding the overarching framing of fossil fuel subsidies and the more specific synergy between the G20 and the OECD helped draw attention to the issue and promote the norm especially at the international but also the domestic levels. The convergence between the institutions was based on the shared elements of their worldviews as economic institutions, institutional interaction and to some degree also their overlapping 
membership. The divergence between the IMF and the OECD was driven by the differences in worldview, policy entrepreneurship among IMF officials and the IMF's greater autonomy from principals, which allowed for the intrainstitutional factors to play a greater role in the case of the IMF. In this way, IO autonomy acted as a scope condition for the other factors. 
